\title{
Can a Conical Implant Successfully Address Complex Anatomy in Primary THA? Radiographs and Hip Scores at Early Followup
}

\author{
Quoqiang Zhang MD, Stuart B. Goodman MD, PhD, William J. Maloney MD, \\ James I. Huddleston III MD
}

Published online: 6 August 2015

(C) The Association of Bone and Joint Surgeons (B) 2015

\begin{abstract}
Background Total hip arthroplasty (THA) in patients with small or abnormal proximal femoral anatomy is challenging as a result of complex anatomic deformities in the hip. It is unclear which stem is the most appropriate for these patients. One possible implant design that may help meet this need is the modified Wagner Cone prosthesis, whose design consists of monoblock cone with splines; however, to our knowledge, no clinical results have been published using this implant.

Questions/purposes We evaluated the hip scores and radiographic results (including signs of osseointegration and subsidence) of complex primary THA using the modified Wagner Cone cementless femoral component in
\end{abstract}

Each author certifies that he or she, or a member of his or her immediate family, has no funding or commercial associations (eg, consultancies, stock ownership, equity interest, patent/licensing arrangements, etc) that might pose a conflict of interest in connection with the submitted article.

All ICMJE Conflict of Interest Forms for authors and Clinical Orthopaedics and Related Research ${ }^{\mathbb{R}}$ editors and board members are on file with the publication and can be viewed on request.

Clinical Orthopaedics and Related Research ${ }^{\circledR}$ neither advocates nor endorses the use of any treatment, drug, or device. Readers are encouraged to always seek additional information, including FDAapproval status, of any drug or device prior to clinical use.

Each author certifies that his or her institution approved the human protocol for this investigation, that all investigations were conducted in conformity with ethical principles of research, and that informed consent for participation in the study was obtained.

Q. Zhang, S. B. Goodman, W. J. Maloney,

J. I. Huddleston III ( $\square)$

Department of Orthopaedic Surgery, Stanford University

Medical Center, 450 Broadway Street, MC 6342, Redwood City,

CA 94063-6342, USA

e-mail: jhuddleston@stanford.edu patients with small or abnormal proximal femoral anatomic proportions.

Methods Between 2006 and 2011, we performed 59 THAs on patients whose femoral geometry precluded the use of standard-sized implants. Of these, 49 (83\%) received the modified Wagner Cone prosthesis. During this time, our indications for use of the Wagner Cone implant in such patients included: femoral neck retroversion, excessive anteversion of the femoral neck, or small proximal femora not suitable for standard implants. Of those, 40 patients with 49 THAs were available for radiographic and clinical followup at a minimum of 3 years, and no patients were lost to followup. The diagnosis included developmental dysplasia of hip (22 patients, 28 hips), secondary trauma or posttuberculosis osteoarthritis (nine patients, 10 hips), and hip disease secondary to other disorders (eight patients, nine hips) and osteonecrosis (one patients, two hips). Two versions of the stem with $135^{\circ}$ (28 hips) or $125^{\circ}$ (21 hips) neck angle versions were used to reestablish normal hip biomechanics. Version angle was chosen based on preoperative templating. Cementless cups with screws were used for the acetabulum. Mean followup was 4 years (range, 3-7 years). Study endpoints were the Harris hip score and radiographic evaluations by a surgeon not involved in the clinical care of the patients (QZ); radiographic analysis included evaluating for the presence or absence of signs of osseointegration (including Engh's criteria) and subsidence.

Results The Harris hip score improved from a mean of 41 \pm 9 preoperatively to a mean of $85 \pm 10$ at last followup (p $<0.01)$. The mean vertical subsidence was $1.5 \pm 1.1 \mathrm{~mm}$. Radiographic evaluation demonstrated stability (no further subsidence) of all implants at last followup. Endosteal spot welds were found in 32 hips (65\%). No progressive radiolucencies were observed. One patient (one hip) underwent 
revision surgery as a result of late infection; no other revisions were performed.

Conclusions The modified Wagner Cone femoral stem has provided improvements in hip scores and promising short-term radiographic results at short-term followup in complex cementless THA associated with abnormal or small femoral anatomical proportions in which standard implants are inappropriate. Longer followup will be needed to see if these results endure. Randomized trials are needed to determine the optimal stem design for these patients. Level of Evidence Level IV, therapeutic study.

\section{Introduction}

Cementless THA has become the preferred choice for advanced hip arthrosis in North America. It is unclear which of the cementless stems might be best for use in patients with small and/or dysplastic proximal femora. A great number of cementless prostheses has been designed and extensively used, including the tapered femoral stem [21]. Khanuja et al. [18] divided tapered femoral stems into three categories: (1) single-wedge prostheses; (2) doublewedge metaphyseal filling stems; and (3) taper round/cone/ rectangular implants. The former two types achieve fixation by a tight metaphyseal fit in one or two planes. The clinical results of these two stems are fairly comparable with reported survivorship as high as $99 \%$ at 20 years of followup with aseptic loosening as the endpoint [23]. Despite the excellent long-term survival, the frequency of thigh pain and proximal stress shielding for some implants remains a concern in some reports $[16,25]$. Moreover, because press-fit is accomplished by metaphyseal fit, when the proximal femur is small or where proximal femoral bone deformity is present, especially when femoral anteversion is excessive, it is difficult to implant standardsized prostheses in an anatomical position.

The third type of taper stem attains stable fixation mainly by press-fit at the metaphyseal-diaphyseal junction through a long, continuous taper in both the mediolateral and the AP planes. Like the former two types of stems, these taper stems can also achieve satisfactory long-term results with an incidence of thigh pain as low as $2 \%$ to $4 \%$ $[4,12]$. The taper cone prosthesis has a narrow round proximal cross-section that facilitates adjustment of the anteversion angle; this implant design is ideal for the femur with proximal femoral deformity such as developmental dysplasia of the hip (DDH) [1, 8, 15, 27, 28, 31].

In 2006, the Wagner Cone femoral stem (Zimmer, Warsaw, IN, USA) was modified to include an enlarged proximal shoulder with sharp longitudinal ribs to enhance stability and osseointegration. A low neck-shaft angle option $\left(125^{\circ}\right)$ was added to address varus anatomy of the proximal femur. Thus far, to our knowledge, no clinical outcomes have been reported with regard to the modified Wagner Cone stem. We present our early results of primary complex THA using the modified Wagner Cone stem.

Specifically, we evaluated the hip scores and radiographic results (including signs of osseointegration and subsidence) of complex primary THA using the modified Wagner Cone cementless femoral component in patients with small or abnormal proximal femoral anatomic proportions.

\section{Materials and Methods}

Our case series was a retrospective study based on of prospectively collected data. All radiographs were analyzed by an orthopaedic surgeon (QZ) who did not participate in any part of the episodes of care of the patients enrolled in the study.

Between 2006 and 2011, we performed 59 THAs on patients whose femoral geometry precluded the use of standard-sized implants. Of these, $49(83 \%)$ received the modified Wagner Cone prosthesis. During this time, our indications for use of the Wagner Cone implant in such patients included: femoral neck retroversion, excessive anteversion of the femoral neck, or small proximal femora not suitable for standard implants. Of those, 40 patients with 49 THAs were available for radiographic and clinical followup at a mean of 4 years (range, 3-7 years). No patients were lost to followup. Monoblock, cylindrical, fully porous-coated stems (Bantam; DePuy, Inc, Warsaw, IN) designed specifically for small proximal femora were used in the other 10 cases. The surgeons chose the Wagner Cone implants for patients with small dimensions and abnormal version, whereas the Bantam stems were used for patients with small proportions but normal femoral neck version.

There were 33 women (40 hips) and seven men (nine hips) with a mean age of 46 years (range, 21-75 years). The average body mass index was $28 \mathrm{~kg} / \mathrm{m}^{2}$ (range, 19-41 $\mathrm{kg} / \mathrm{m}^{2}$ ). Nine patients received two-stage bilateral hip arthroplasty. The diagnoses (Table 1) included hip dysplasia (22 patients, 28 hips), traumatic or posttuberculosis arthritis (nine patients, 10 hips), and hip arthritis secondary to special disorders (eight patients, nine hips) including dwarfism, fibrous dysplasia of bone, juvenile rheumatoid arthritis, poliomyelitis, and Perthes' disease. One patient had postcollapse femoral head osteonecrosis (two hips). All the subjects in our series had one or more structural abnormalities including increased femoral anteversion or a small proximal femoral canal resulting from osteotomy or growth abnormality. 
Table 1. Etiology of arthrosis

\begin{tabular}{lc}
\hline Diagnosis & $\begin{array}{l}\text { Number of } \\
\text { hips }\end{array}$ \\
\hline Dysplasia & 28 \\
Posttraumatic arthrosis & 9 \\
Postinfectious arthrosis (tuberculosis) & 1 \\
Other (Perthes' disease, juvenile rheumatoid arthritis, & 9 \\
$\quad$ dwarfism, poliomyelitis, fibrous dysplasia of bone) & \\
Osteonecrosis & 2 \\
\hline
\end{tabular}

For all patients, preoperative templating was performed by the surgical team to select the most appropriate size of implant. Wagner Cone stems with $135^{\circ}$ or $125^{\circ}$ neck angle version were used according to the offset of the normal contralateral hip or, if abnormal, to reestablish normal hip biomechanics. The patients were placed in the lateral decubitus position and a modified direct lateral or posterior approach was used. Flexible and conical reamers were used to ream the femoral medullary canal. The stem was implanted in $10^{\circ}$ to $15^{\circ}$ anteversion using the epicondylar axis as a guide, irrespective of the preoperative femoral anteversion. The $125^{\circ}$ stem was used in 21 hips and the $135^{\circ}$ stem was implanted in 28 hips. For one patient with complete dislocation of the hip, shortening subtrochanteric osteotomy and trial reduction were performed according to the preoperative plan. The acetabulum was reamed and a Trilogy or Trabecular Metal (porous tantalum coating on a titanium alloy backing; Zimmer) cup was press-fit and stabilized by screws. Socket design was chosen based on surgeon preference. A 28- or 32-mm metal femoral head and corresponding Longevity (Zimmer) highly crosslinked polyethylene liner were used. There were no intraoperative complications.

All patients began weightbearing as tolerated with a walker or crutches and progressed to a cane as tolerated. All the patients were clinically and radiologically evaluated at 6 weeks, 3 months, and 6 months (as necessary) and 1 year after the operation and then on an annual basis. The surgeon and an independent physical therapist (SI) evaluated the patient at each followup visit. Harris hip scores were calculated.

Radiographs included standardized AP pelvis, frog-leg, and crosstable lateral views. All the measurements were performed with a digital ruler by the same orthopaedic fellow who was not involved in the surgery. We used the radiographic criteria by Engh et al. [7] to evaluate stem fixation. Gruen zones were used for anatomical description of the radiographic findings [7, 13]. We modified Engh et al.'s [7] method to evaluate subsidence of the stem (Fig. 1). Stem subsidence was quantified by drawing a line (a) along the longitudinal axis of the stem, and then another

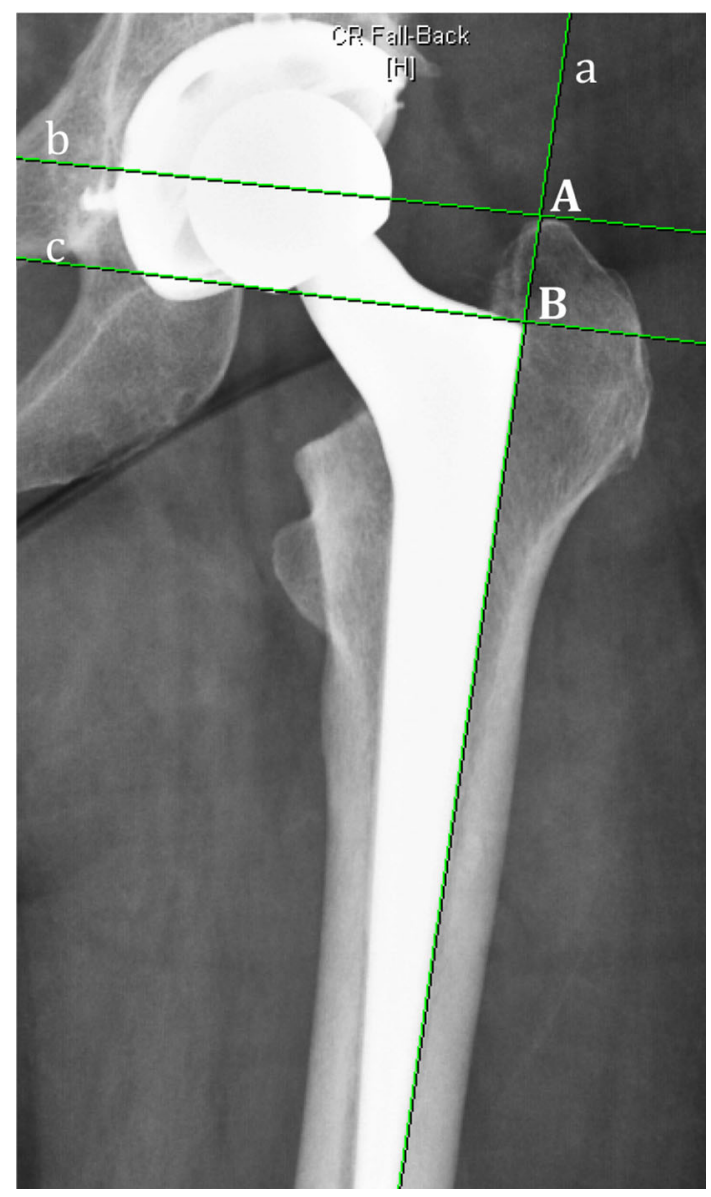

Fig. 1 Stem subsidence was quantified by drawing a line (a) along the longitudinal axis of the stem, and then another two lines, perpendicular to line A ( $\mathrm{b}$ and $\mathrm{c}$ ) and going through the tip of the great trochanter and the shoulder of the stem, respectively. The distance between the cross-sections A and B was measured and the change in the distance over time was recorded during followup.

two lines perpendicular to line $\mathrm{A}$ (b and $\mathrm{c}$ ) and going through the tip of the great trochanter and the shoulder of the stem, respectively. The distance between cross-sections $\mathrm{A}$ and $\mathrm{B}$ was measured and the change in the distance over time was recorded during followup (Fig. 1).

Statistical Analysis

Data were subjected to a paired t-test for statistical analysis.

\section{Results}

Hip Scores and Clinical Findings

The Harris hip score improved from $41 \pm 9$ (range, 24-56) preoperatively to $85 \pm 10$ (range, 71-100) at final followup 
Table 2. Results of Harris hip score and stem subsidence

\begin{tabular}{|c|c|c|c|}
\hline Items & Results & $\mathrm{t}$ & $\mathrm{p}$ value \\
\hline \multicolumn{4}{|l|}{ Harris hip score } \\
\hline Preoperation & $41 \pm 9$ & 23 & $<0.001 *$ \\
\hline Postoperation & $85 \pm 10$ & & \\
\hline \multicolumn{4}{|l|}{ Final followup } \\
\hline Average increment & $44 \pm 14$ & & \\
\hline \multicolumn{4}{|c|}{ Average distance of subsidence (ADS, mm) } \\
\hline General ADS & $2 \pm 1$ & & \\
\hline $125 / / 135^{\dagger}$ & $2 \pm 1 / 1 \pm 1$ & 0.88 & 0.382 \\
\hline ADS before 12 weeks & $1 \pm 1$ & & \\
\hline $125 / / 135^{\dagger}$ & $1 \pm 1 / 1 \pm 1$ & 0.56 & 0.580 \\
\hline ADS after 12 weeks & $0.1 \pm 0.1$ & & \\
\hline $125 / / 135^{\dagger}$ & $0.2 \pm 0.2 / 0.04 \pm 0.3$ & 1.89 & 0.065 \\
\hline \multicolumn{4}{|c|}{ Stem subsidence in terms of case distribution } \\
\hline$<2 \mathrm{~mm} / 2-3 \mathrm{~mm} / 3-4 \mathrm{~mm} />4 \mathrm{~mm}$ & $18 / 9 / 1 / 1$ & & \\
\hline $125: 135^{*}$ & $8: 10 / 3: 6 / 0: 1 / 1: 0$ & & \\
\hline
\end{tabular}

Results are mean $\pm \mathrm{SD} ; *$ comparison between the preoperative Harris hip score and score on last followup visit; ${ }^{\dagger}$ comparison between stems with $125^{\circ}$ and $135^{\circ}$ neck angle; ${ }^{\ddagger}$ comparison between stems with $125^{\circ}$ and $135^{\circ}$ neck angle in terms of case distribution.

with an average increment of $44 \pm 14(\mathrm{p}<0.01)$ (Table 2). Apart from one patient whose hip was revised as a result of late postoperative infection, the remaining patients reported improvement in pain relief and hip function. Two patients developed trochanteric bursitis, which was treated by physical therapy; one also had iliopsoas tendonitis, which was treated by surgical release of the iliopsoas tendon. One patient received two-stage revision arthroplasty of the hip as a result of late infection 3 years after operation. None of the hips failed as a result of aseptic loosening.

\section{Radiographic Analysis}

The radiographs at the last followup visit revealed endosteal spot welds in 32 hips $(65 \%)$ with most in Gruen Zones 2, 3, 5, and 6. In nine hips, spot welds were also observed in Gruen Zones 1 and 7. Hips that did not have obvious spot welds or other features of osseointegration were considered to have fibrous stable fixation (17 hips [35\%]). No stems were classified as loose. Seventeen hips (35\%) showed cortical hypertrophy at the level of the middle onethird of the stem. The radiographs taken at latest followup visits showed further densification in this area. In some hips, the bands of increased density could be found along the whole implant (Fig. 2). No progressive radiolucencies or distal pedestals were observed.

Definite subsidence occurred in 11 hips (22\%). The mean subsidence was $1.5 \pm 1.1 \mathrm{~mm}$ (Table 2). Specifically, 18 hips had subsidence of less than $2 \mathrm{~mm}$; nine had subsidence of 2 to $3 \mathrm{~mm}$ (Table 2). In all hips, stem subsidence took place during the initial 8 to 12 weeks after operation, accounting for $93 \%$ of overall subsidence distance in this time (Table 2). All stems eventually stabilized based on radiographs showing no stem subsidence between time points at least 3 months apart. There was no difference in subsidence with the numbers available between stems with a neck angle of $125^{\circ}(1.6 \pm 1.1 \mathrm{~mm})$ and those with a neck angle of $135^{\circ}(1.4 \pm 1.0 \mathrm{~mm})$. Two patients had subsidence of $4 \mathrm{~mm}$ and $5 \mathrm{~mm}$, respectively. The patient whose stem subsided $5 \mathrm{~mm}$ had DDH and previous osteotomy of the acetabulum and the proximal femur. As a result, the femoral canal was deformed and enlarged and a small gap existed between the stem and the femoral cortex at the middle one-third of the stem. The hip with subsidence of $4 \mathrm{~mm}$ had juvenile chronic arthritis and his femur had notable osteopenia with a wide femoral canal. Both of these implants showed definite evidence of prosthesis osseointegration at 1-year followup. No subject developed joint instability as a result of stem subsidence.

\section{Discussion}

THA in patients with small femora or bone deformity can be technically challenging. The optimal stem design in these patients is unknown. A number of studies have reported that modular prostheses such as the S-ROM (DePuy, Inc) can help deal with these anatomical challenges $[2,5,6,11,19,30]$; however, a theoretical disadvantage includes the potential for metal corrosion 
Fig. 2A-D These images show the preoperative $(\mathbf{A}-\mathbf{B})$ and postoperative $(\mathbf{C}-\mathbf{D})$ radiographs of a patient with acetabular dysplasia and posttraumatic hip arthrosis resulting in complex proximal femoral anatomy amenable to reconstruction with the Wagner Cone femoral prosthesis.
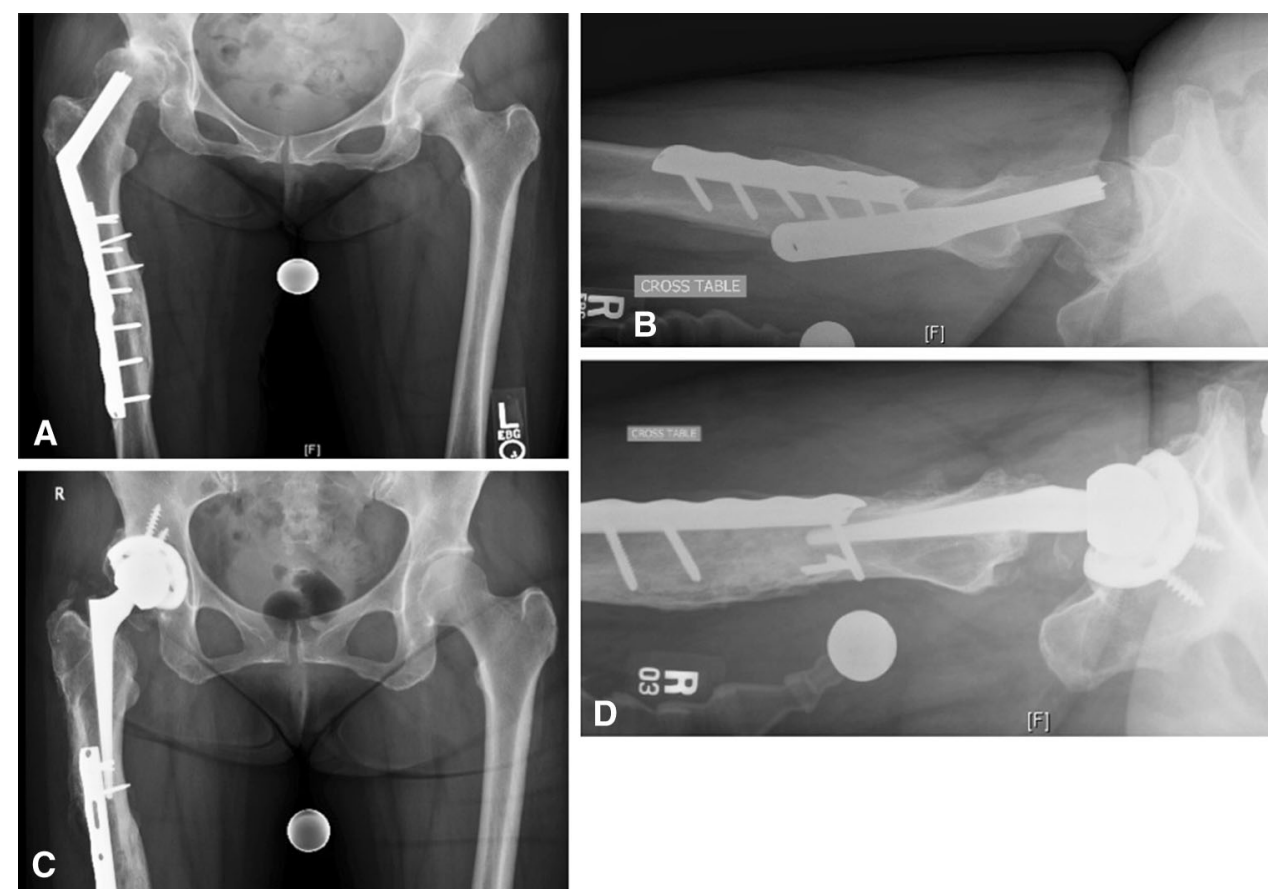

with modularity $[9,20]$. The Wagner Cone stem can accommodate small or deformed femora because of its proximal conical, tapered design. This design facilitates adjustment of stem position in hips with excessive native femoral anteversion, a point noted previously [1, 27]. However, to our knowledge, no studies have evaluated this implant's results in a series of difficult primary THAs. This study demonstrated that complex THA using the modified Wagner Cone femoral stem could achieve radiographic stability (without any intraoperative femoral fractures) and improvements in clinical hip scores at short-term followup.

This study has several limitations. First, as a retrospective review of prospectively collected data, it suffers from selection bias. Some patients with similar deformities (smaller proportions) were treated with the Bantam (DePuy, Inc) stem during the study period. Given that these patients had less complex deformities (no version abnormalities) than the patients treated with Wagner Cones, it seems likely that the conical prostheses would have fared well in these hips with more normal anatomy. Second, longer followup is needed to determine if these short-term results will endure. Lastly, because we only measured axial movement (subsidence) of the stems, we cannot comment on stem rotation in the short-term.

The patients in this study should comparable improvement in their hip scores compared to previous reports of patients who underwent complex, primary, cementless, total hip arthroplasty with conical prostheses as well as modular prostheses [1, 2, 6, 8, 11, 15, 19, 27, 28, 30, 31]. Despite predictable success with similar stems, it remains critically important to systematically report clinical and radiographic results whenever new technology is introduced.

Stem subsidence is common with cementless stems and can lead to failure of osseointegration, especially in complex primary THA and revision arthroplasty using taper stems [3, 22, 32]. Several clinical studies have suggested that early subsidence of less than 4 to $5 \mathrm{~mm}$ did not affect final stem stability, early weightbearing, or the final clinical outcome [10, 14, 24, 26, 29]. The stem design may be important in achieving stability after initial subsidence, because a conical geometry may be more successful than a cylindrical one. In this series, minor stem subsidence mainly occurred in the initial 12 weeks after operation. Precise preoperative templating and intraoperative evaluation of femoral stem stability can minimize the possibility of stem subsidence, although bony expansion from high hoop stresses in the first 72 hours after the operation and patient activity may also contribute to the amount of subsidence. Fixation of the Wagner Cone stem is different from traditional taper stems and those with distal fixation. The conical-shaped proximal cross-section provides enhanced bone-implant contact area as compared with stems with a rectangular cross-section, thereby enhancing stability and fixation and facilitating the correction of excessive anteversion [17].

We found that that the modified Wagner Cone stem femoral component can achieve radiographic stability and substantial improvements in hip scores at short-term followup in complex THA associated with abnormal or small femoral anatomical proportions in which standard implants are not appropriate. Although longer followup will be 
needed to see if the results of this study endure, randomized trials will help to determine the optimal stem design for these patients.

Acknowledgments We thank Susanne Imrie PT, for her assistance in assessing patients in clinic. We also thank Katherine Hwang for her help in collecting and retrieving the data.

\section{References}

1. Alexander S, Annemarie S, Hohenberger G. Long-term results of the Wagner cone prosthesis. Int Orthop. 2009;33:53-58.

2. Biant LC, Bruce WJ, Assini JB, Walker PM, Walsh WR. Primary total hip arthroplasty in severe developmental dysplasia of the hip. Ten-year results using a cementless modular stem. $J$ Arthroplasty. 2009;24:27-32.

3. Bohm P, Bischel O. The use of tapered stems for femoral revision surgery. Clin Orthop Relat Res. 2004;420:148-159.

4. Bourne RB, Rorabeck CH, Patterson JJ, Guerin J. Tapered titanium cementless total hip replacements: a 10- to 13-year followup study. Clin Orthop Relat Res. 2001;393:112-120.

5. Buly R. The S-ROM stem. Versatility of stem/sleeve combinations and head options. Orthopedics. 2005;28:1025-1032.

6. Christie MJ, DeBoer DK, Trick LW, Brothers JC, Jones RE, Vise GT, Gruen TA. Primary total hip arthroplasty with use of the modular S-ROM prosthesis. J Bone Joint Surg Am. 1999;81: 1707-1716.

7. Engh CA, Massin P, Suthers KE. Roentgenographic assessment of the biologic fixation of porous-surfaced femoral components. Clin Orthop Relat Res. 1990;257:107-128.

8. Faldini C, Miscione MT, Chehrassan M, Acri F, Pungetti C, d'Amato M, Luciani D, Giannini S. Congenital hip dysplasia treated by total hip arthroplasty using cementless tapered stem in patients younger than 50 years old: results after 12-years followup. J Orthop Traumatol. 2011;12:213-218.

9. Gilbert JL, Buckley CA, Jacobs JJ, Bertin KC, Zernich MR. Intergranular corrosion-fatigue failure of cobalt-alloy femoral stems. A failure analysis of two implants. J Bone Joint Surg Am. 1994;76:110-115.

10. Girard J, Blairon A, Wavreille G, Migaud H, Senneville E, Le Béguece P. Stem subsidence after total hip revision: 183 cases at 5.9 years follow-up. Orthop Traumatol Surg Res. 2011;97: $121-126$.

11. Gorski JM. Modular noncemented total hip arthroplasty for congenital dislocation of the hip. Clin Orthop Relat Res. 1988;228:110-116.

12. Grübl A, Chiari C, Giurea A, Gruber M, Kaider A, Marker M, Zehetgruber H, Gottsauner-Wolf F. Cementless total hip arthroplasty with the rectangular titanium Zweymuller stem. A concise follow-up, at a minimum of fifteen years, of a previous report. J Bone Joint Surg Am. 2006;88:2210-2215.

13. Gruen TA, McNeice GM, Amstutz HC. 'Modes of failure' of cemented stem-type femoral components. A radiographic analysis of loosening. Clin Orthop Relat Res. 1979;141:17-27.

14. Grunig R, Morscher E, Ochsner PE. Three-to 7-year results with the uncemented SL femoral revision prosthesis. Arch Orthop Trauma Surg. 1997;116:187-197.
15. Ström H, Mallmin H, Milbrink J, Petrén-Mallmin M, Nivbrant B, Kolstad K. The Cone hip stem: a prospective study of 13 patients followed for 5 years with RSA. Acta Orthop Scand. 2003;74: 525-530.

16. Incavo SJ, Havener T, Benson E, McGrory BJ, Coughlin KM, Beynnon BD. Efforts to improve cementless femoral stems in THR: 2- to 5-year follow-up of a high-offset femoral stem with distal stem modification (Secur-Fit Plus). J Arthroplasty. 2004;19:61-67.

17. Kendrick JBI, Noble PC, Tullos H. Distal stem design and the torsion stability of cementless femoral stems. J Arthroplasty. 1995;10:463-469.

18. Khanuja HS, Vakil JJ, Goddard MS, Mont MA. Cementless femoral fixation in total hip arthroplasty. J Bone Joint Surg Am. 2011;93:500-509.

19. Kido K, Fujioka M, Takahashi K, Ueshima K, Goto T, Kubo T. Shortterm results of the S-ROM-A femoral prosthesis. J Arthroplasty. 2009;24:1193-1199.

20. Lakstein D, Eliaz N, Levi O, Backstein D, Kosashvili Y, Safir O, Gross AE. Fracture of cementless femoral stems at the mid-stem junction in modular revision hip arthroplasty systems. $J$ Bone Joint Surg Am. 2011;93:57-65.

21. Lombardi AV, Berend KR, Mallory TH, Skeels MD, Adams JB. Survivorship of 2000 tapered titanium porous plasma-sprayed femoral components. Clin Orthop Relat Res. 2009;467:146-154.

22. McInnis DP, Horne G, Devane PA. Femoral revision with a fluted, tapered, modular stem seventy patients followed for a mean of 3.9 years. J Arthroplasty. 2006;21:372-380.

23. McLaughlin JR, Lee KR. Total hip arthroplasty with an uncemented tapered femoral component. J Bone Joint Surg Am. 2008;90:1290-1296.

24. Morscher E. Experience with the press-fit cup and press-fit gliding stem. In: Kusswetter W, ed. Noncemented Total Hip Replacement. Proceedings of International Symposium; 1990. Tübingen, Germany; New York, NY, USA; Stuttgart, Germany: Thieme; 1991:221-231.

25. Müller LA, Wenger N, Schramm M, Hohmann D, Forst R, Carl HD. Seventeen-year survival of the cementless CLS Spotorno stem. Arch Orthop Trauma Surg. 2009;130:269-275.

26. Rao RR, Sharkey PF, Hozack WJ, Eng K, Rothman RH. Immediate weight bearing after uncemented total hip arthroplasty. Clin Orthop Relat Res. 1998;349:156-162.

27. Claramunt RT, Marqués F, León A, Vilà G, Mestre C, Verdié LP. Total hip replacement with an uncemented Wagner cone stem for patients with congenital hip dysplasia. Int Orthop. 2011;35: $1767-1770$

28. Schuh A, Schraml A, Hohenberger G. Long-term results of the Wagner cone prosthesis. Int Orthop. 2009;33:53-58.

29. Sorrentino R, Apicella D, Riccio C, Gherlone E, Zarone F, Aversa R, Garcia-Godoy F, Ferrari M, Apicella A. Nonlinear visco-elastic finite element analysis of different porcelain veneers configuration. J Biomed Mater Res B Appl Biomater. 2009;91: 727-736.

30. Traina F, De Fine M, Tassinari E, Sudanese A, Calderoni PP, Toni A. Modular neck prostheses in DDH patients: 11-year results. J Orthop Sci. 2011;16:14-20.

31. Wagner H, Wagner M. Cone prosthesis for the hip joint. Arch Orthop Trauma Surg. 2000;120:88-95.

32. Weeden SH, Paprosky WG. Minimal 11-year follow-up of extensively porous-coated stems in femoral revision total hip arthroplasty. J Arthroplasty. 2002;17(Suppl 1):134-137. 